\title{
Astrocytes and memory
}

\author{
Oğuzhan Kütük (10 \\ Psychologist, Istanbul, Turkey
}

\begin{abstract}
Although their presence in the brain has been discovered years ago, astrocytes have been overshadowed by neurons due to lack of research. However, thanks to studies conducted in the last 20 years, it has become clear that astrocytes play a role in many functions of the brain such as memory and learning. In addition, recent findings have shown that astrocytes are associated with learning, memory impairments, and psychiatric disorders. These studies may provide new insight into certain issues left unsolved by neurons.

Keywords: Astrocytes, glial cells, gliotransmitters, memory.
\end{abstract}

\section{GLIAL CELLS}

There are two types of nerve cells in the brain: neurons and glia. In the mid-19 ${ }^{\text {th }}$ century, Rudolf Virchow, a German anatomist, first described this new cell type and named them glia (glue), believing these cells acted as a sort of adhesive for the nervous system. ${ }^{[1]}$ Glial cells are necessary for the development, function, and transmission of the nervous system. There are three main types of glial cells in the central nervous system (CNS): astrocytes, microglia, and oligodendrocytes. Neurons are associated with glia for physical support, nutrient supply, and clearing of extracellular molecules, as well as for enhancing and modulating signal transduction. ${ }^{[2]}$ In fact, every neuron is protected by some type of glial cell. ${ }^{[3]}$ At the same time, glial cells, like neurons, synthesize and release a large number of molecules. These molecules play a significant role in controlling the microarchitecture, neuronal structure and metabolism, as well as contributing to the regulation of the electrical activity of neurons. These molecules, which are synthesized and released by glial cells, are referred to as "gliotransmitters". ${ }^{[4-6]}$

\section{THE ROLE OF ASTROCYTES IN THE BRAIN}

Astrocytes are the most abundant of the glial cells and are in continuous association with most cell types in the CNS. ${ }^{[7]}$

Astrocytes have the ability to receive signals from neurons through membrane receptors and convert the received information to calcium $\left(\mathrm{Ca}^{2+}\right)$ excitability. The ability of astrocytes to release extracellular signaling molecules regulated by this $\mathrm{Ca}^{2+}$ excitability indicates that they play a very active role in the CNS. This concept of regulated transmitter release from astrocytes to neurons is commonly known as gliotransmission. ${ }^{[8,9]}$ The most abundant gliotransmitters are glutamate, D-serine, and adenosine triphosphate (ATP). ${ }^{[7,8,10]}$

Received: January 28, 2020 Accepted: March 05, 2020 Published online: August 25, 2020 
Astrocytes are especially important in the homeostasis of neurotransmitters in the brain. They contribute to the removal of many neurotransmitters from the synaptic cleft, their metabolism (glucose and lactate), and the reuptake of the two most common neurotransmitters in the brain (glutamate and gamma-aminobutyric acid [GABA]). They also play an especially significant role in preventing the accumulation and toxicity of glutamate, an important excitatory neurotransmitter, in the brain. While $20 \%$ of glutamate that is released during synaptic transport is retaken by neurons, the remaining $80 \%$ is retaken by perisynaptic astrocytes. ${ }^{[11-13]}$ Removal of glutamate from the extracellular site is vital for protection against excitotoxicity, as well as initiating the glutamate-glutamine cycle, an essential cycle for re-synthesis in neurons. ${ }^{[4,11]}$ Astrocytes, which are steadfast helpers of neurons in carrying out several functions in the brain, sometimes directly or indirectly contribute to learning and memory functions. ${ }^{[14]}$

\section{THE ROLE OF GLIOTRANSMITTERS IN MEMORY}

The association of astrocytes with memory is mostly through secreted gliotransmitters. One of these gliotransmitters is GABA, the main inhibitory transmitter of the brain. Astrocytes provide reuptake of GABA from synapses, without which the establishment of synaptic communication in neurons would be impossible. ${ }^{[15]}$ Inadequate or excessive GABA secretion may reduce synaptic plasticity and cause memory impairment in domains including spatial memory, working memory, and fear-related memory. ${ }^{[16-19]}$ Another significant gliotransmitter is glutamate, known as the major excitatory molecule of the brain. Likewise, synaptic communication cannot be established without glutamate reuptake. Glutamate is released by both astrocytes and neurons and taken up by astrocytes from the synaptic cleft and returned to perisynaptic neurons for reuse. ${ }^{20]}$ Glutamate plays a crucial role not only in synaptic transmission but also in synaptic plasticity through the activation of $\alpha$-amino-3-hydroxy-5-methyl-4isoxazolepropionic acid (AMPA) and N-methyl$\mathrm{d}$-aspartate (NMDA) receptors. Glutamate has been shown to strengthen memory, ${ }^{[21]}$ and has also been associated with cognitive deficits and psychiatric disorders - especially schizophrenia and Alzheimer's. ${ }^{[22-24]}$ D-serine is another molecule released by astrocytes ${ }^{[25-27]}$ and binds to NMDA receptors. ${ }^{[28]} \mathrm{D}$-serine is involved in most long-term memory processes including NMDA-receptor-dependent synaptic plasticity, regulation of long-term potentiation (LTP), and hippocampal neurogenesis. ${ }^{[26,29,30]}$ Studies have also demonstrated that $\mathrm{D}$-serine is involved in spatial memory formation and is associated with age-related memory loss. ${ }^{[31,32]}$ Recent studies have indicated that $\mathrm{D}$-serine can also be released by neurons and regulate the formation of synaptic plasticity. ${ }^{[33]}$ Adenosine triphosphate, another molecule released by astrocytes, is released in response to glutamate and plays a role in the formation of neural stem cells in the hippocampus. ${ }^{[34,35]}$ Glutamate is taken up by astrocytes and converted by glutamine synthetase to glutamine, another important molecule of the nervous system, which is retaken by neurons to carry out its functions. The relationship between glutamine and memory was revealed in an experimental study on mice. The study found that there was a decrease in glutamine synthetase in astrocytes in the prefrontal cortex of Alzheimer-induced mice. ${ }^{[23]}$

\section{OTHER ASTROCYTIC FUNCTIONS THAT DIRECTLY AFFECT MEMORY}

As mentioned before, the relationship between molecules and memory is more indirect. However, the relationship of some substances released by astrocytes is more directly linked to memory. ${ }^{[36]}$ One of these substances released by astrocytes is lactate. Neurons require glucose/lactate to carry out their functions. In one study, lactate released from astrocytes in the hippocampus was shown to play an important role in emotional memory formation in rats and learning in chicks. ${ }^{[37,38]}$ In addition, these studies reported that the release of lactate from astrocytes was required for long-term memory formation (but not required for short-term memory formation) and that lactate injection to the intrahippocampal region enhanced memory. ${ }^{[37,38]}$ Orally administered glucose (glucose can be converted to lactate) was found to increase cognitive functions while enhancing memory in humans and rats, and 
improve verbal memory in healthy young and old people. ${ }^{[39-42]}$ Another molecule associated with memory and learning is $\mathrm{K}^{+}$. One study demonstrated that removal of $\mathrm{K}^{+}$from the synaptic cleft contributed to short-term plasticity formation. ${ }^{[43]}$

More important evidence of the role of astrocytes in memory was found in another experimental study on rats. In the experiment, it was found that the number of astrocytes in the CA3 region of rats increased during the Morris water-maze test (used in learning and memory experiments. ${ }^{[4]}$ In a recent in-vivo study by Stehberg et al., ${ }^{[45]}$ gliotransmitter release of astroglial connexin 43-hemichannels in the basolateral amygdala region of rats was blocked during memory consolidation (after presenting stimuli to be remember later); 24 hours later, amnesia was observed in the rats. After the effects of amnesia, the rats were injected a cocktail consisting of gliotransmitters such as glutamate, D-serine, glutamine, ATP, and glycine, and learning capacity was recovered.

Another recently published study, Pinto-Duarte et al. ${ }^{[46]}$ studied genetically engineered mice that were lacking a receptor called type 2 inositol 1,4,5-trisphosphate $\left(\mathrm{IP}_{3} \mathrm{R} 2\right)$ to understand the relationship between astrocytes and long-term memory. Astrocytes rely on these receptors to release calcium for communication. ${ }^{[47,48]}$ Mice lacking $\mathrm{Ip}_{3} \mathrm{R} 2$ receptor $\left(\mathrm{Ip}_{3} \mathrm{R} 2^{--}\right)$were tested $24-48$ hours after learning processes, and the results were similar compared to the performance of normal mice. However, when researchers retested the mice 2-4 weeks later, mice lacking the $\mathrm{Ip}_{3} \mathrm{R} 2$ receptor performed much worse than normal mice, while normal mice showed better performance compared to their first test. This indicates that mice lacking $\mathrm{Ip}_{3} \mathrm{R} 2$ receptors significantly lost their memory consolidation abilities. [46] The increasing understanding of the relationship between astrocytes and memory can contribute to the future development of drugs to manipulate memory consolidation and treat memory-related disorders. ${ }^{[5,46]}$

\section{Declaration of conflicting interests}

The author declared no conflicts of interest with respect to the authorship and/or publication of this article.

\section{Funding}

The author received no financial support for the research and/or authorship of this article.

\section{REFERENCES}

1. Webster HD, Åström KE, editors. Gliogenesis. Berlin: Springer; 2009.

2. Perea G, Navarrete M, Araque A. Perea G, Navarrete $\mathrm{M}$, Araque A. Tripartite synapses: astrocytes process and control synaptic information. Trends Neurosci 2009;32:421-31.

3. Russell P. The Brain Book: Know Your Own Mind and How to Use. 1st ed. New York: Routledge; 1984.

4. Angulo MC, Le Meur K, Kozlov AS, Charpak S, Audinat E. GABA, a forgotten gliotransmitter. Prog Neurobiol 2008;86:297-303.

5. Orellana JA, Stehberg J. Hemichannels: new roles in astroglial function. Front Physiol 2014;5:193.

6. Verkhratsky A, Olabarria M, Noristani HN, Yeh CY, Rodriguez JJ. Astrocytes in Alzheimer's disease. Neurotherapeutics 2010;7:399-412.

7. Harada K, Kamiya T, Tsuboi T. Gliotransmitter Release from Astrocytes: Functional, Developmental, and Pathological Implications in the Brain. Front Neurosci 2016;9:499.

8. Parpura V, Basarsky TA, Liu F, Jeftinija K, Jeftinija S, Haydon PG. Glutamate-mediated astrocyte-neuron signalling. Nature 1994;369:744-7.

9. Bezzi P, Gundersen V, Galbete JL, Seifert G, Steinhäuser C, Pilati E, et al. Astrocytes contain a vesicular compartment that is competent for regulated exocytosis of glutamate. Nat Neurosci 2004;7:613-20.

10. Parri H, Gould T, Crunelli V. Spontaneous astrocytic $\mathrm{Ca} 2+$ oscillations in situ drive NMDAR-mediated neuronal excitation. Nat Neurosci 2001;4:803-12.

11. Bélanger M, Magistretti PJ. The role of astroglia in neuroprotection. Dialogues Clin Neurosci 2009;11:281-95.

12. Coulter DA, Eid T. Astrocytic regulation of glutamate homeostasis in epilepsy. Glia 2012;60:1215-26.

13. Verkhratsky A, Kirchhoff F. Glutamate-mediated neuronal-glial transmission. J Anat 2007;210:651-60.

14. Moraga-Amaro R, Jerez-Baraona JM, Simon F, Stehberg J. Role of astrocytes in memory and psychiatric disorders. J Physiol Paris 2014;108:24051.

15. Lee M, McGeer EG, McGeer PL. Mechanisms of GABA release from human astrocytes. Glia 2011;59:1600-11.

16. Whissell PD, Eng D, Lecker I, Martin LJ, Wang DS, Orser BA. Acutely increasing $\delta G A B A(A)$ receptor activity impairs memory and inhibits synaptic plasticity in the hippocampus. Front Neural Circuits 2013;7:146.

17. Begenisic T, Baroncelli L, Sansevero G, Milanese M, Bonifacino T, Bonanno G, et al. Fluoxetine in 
adulthood normalizes GABA release and rescues hippocampal synaptic plasticity and spatial memory in a mouse model of Down syndrome. Neurobiol Dis 2014;63:12-9.

18. Makkar SR, Zhang SQ, Cranney J. Behavioral and neural analysis of GABA in the acquisition, consolidation, reconsolidation, and extinction of fear memory. Neuropsychopharmacology 2010;35:1625-52.

19. Thanapreedawat $P$, Kobayashi $H$, Inui $N$, Sakamoto $\mathrm{K}$, Kim M, Yoto A, et al. GABA affects novel object recognition memory and working memory in rats. $\mathrm{J}$ Nutr Sci Vitaminol (Tokyo) 2013;59:152-7.

20. Porter JT, McCarthy KD. Hippocampal astrocytes in situ respond to glutamate released from synaptic terminals. J Neurosci 1996;16:5073-81.

21. Pocivavsek A, Wu HQ, Potter MC, Elmer GI, Pellicciari $\mathrm{R}$, Schwarcz R. Fluctuations in endogenous kynurenic acid control hippocampal glutamate and memory. Neuropsychopharmacology 2011;36:2357-67.

22. Allen NJ, Barres BA. Signaling between glia and neurons: focus on synaptic plasticity. Curr Opin Neurobiol 2005;15:542-8.

23. Kulijewicz-Nawrot M, Syková E, Chvátal A, Verkhratsky A, Rodríguez JJ. Astrocytes and glutamate homoeostasis in Alzheimer's disease: a decrease in glutamine synthetase, but not in glutamate transporter-1, in the prefrontal cortex. ASN Neuro 2013;5:273-82.

24. Spangaro M, Bosia M, Zanoletti A, Bechi M, Cocchi $\mathrm{F}$, Pirovano $\mathrm{A}$, et al. Cognitive dysfunction and glutamate reuptake: effect of EAAT2 polymorphism in schizophrenia. Neurosci Lett 2012;522:151-5.

25. Martineau M. Gliotransmission: focus on exocytotic release of L-glutamate and D-serine from astrocytes. Biochem Soc Trans 2013;41:1557-61.

26. Henneberger C, Papouin T, Oliet SH, Rusakov DA. Long-term potentiation depends on release of D-serine from astrocytes. Nature 2010;463:232-6.

27. Kang N, Peng H, Yu Y, Stanton PK, Guilarte TR, Kang J. Astrocytes release $\mathrm{D}$-serine by a large vesicle. Neuroscience 2013;240:243-57.

28. Papouin T, Ladépêche L, Ruel J, Sacchi S, Labasque $M$, Hanini $M$, et al. Synaptic and extrasynaptic NMDA receptors are gated by different endogenous coagonists. Cell 2012;150:633-46.

29. Shigetomi E, Jackson-Weaver O, Huckstepp RT, O'Dell TJ, Khakh BS. TRPA1 channels are regulators of astrocyte basal calcium levels and long-term potentiation via constitutive $\mathrm{D}$-serine release. $\mathrm{J}$ Neurosci 2013;33:10143-53.

30. Sultan S, Gebara EG, Moullec K, Toni N. D-serine increases adult hippocampal neurogenesis. Front Neurosci 2013;7:155.

31. Zhang Z, Gong N, Wang W, Xu L, Xu TL. Bellshaped D-serine actions on hippocampal longterm depression and spatial memory retrieval.
Cereb Cortex 2008;18:2391-401.

32. Mothet JP, Rouaud E, Sinet PM, Potier B, Jouvenceau A, Dutar P, et al. A critical role for the glial-derived neuromodulator $\mathrm{D}$-serine in the age-related deficits of cellular mechanisms of learning and memory. Aging Cell 2006;5:267-74.

33. Rosenberg D, Artoul S, Segal AC, Kolodney G, Radzishevsky I, Dikopoltsev E, et al. Neuronal D-serine and glycine release via the Asc-1 transporter regulates NMDA receptor-dependent synaptic activity. J Neurosci 2013;33:3533-44.

34. Stout $C$, Charles A. Modulation of intercellular calcium signaling in astrocytes by extracellular calcium and magnesium. Glia 2003;43:265-73.

35. Cao X, Li LP, Qin XH, Li SJ, Zhang M, Wang Q, et al. Astrocytic adenosine 5'-triphosphate release regulates the proliferation of neural stem cells in the adult hippocampus. Stem Cells 2013;31:1633-43.

36. Pellerin L. How astrocytes feed hungry neurons. Mol Neurobiol 2005;32:59-72.

37. Newman LA, Korol DL, Gold PE. Lactate produced by glycogenolysis in astrocytes regulates memory processing. PLoS One 2011;6:e28427.

38. Suzuki A, Stern SA, Bozdagi O, Huntley GW, Walker $\mathrm{RH}$, Magistretti PJ, et al. Astrocyte-neuron lactate transport is required for long-term memory formation. Cell 2011;144:810-23.

39. Gold PE. Role of glucose in regulating the brain and cognition. Am J Clin Nutr 1995;61:987S-95S.

40. Messier C. Glucose improvement of memory: a review. Eur J Pharmacol 2004;490:33-57.

41. Coccoz V, Sandoval AV, Stehberg J, Delorenzi A. The temporal dynamics of enhancing a human declarative memory during reconsolidation. Neuroscience 2013;246:397-408.

42. Manning CA, Ragozzino ME, Gold PE. Glucose enhancement of memory in patients with probable senile dementia of the Alzheimer's type. Neurobiol Aging 1993;14:523-8.

43. Sibille J, Pannasch U, Rouach N. Astroglial potassium clearance contributes to short-term plasticity of synaptically evoked currents at the tripartite synapse. J Physiol 2014;592:87-102.

44. Mehrdad J, Yousef S, Ahmad H, Nasser N, Abbas P. (2008). Working Memory Learning Method and Astrocytes Number in Different Subfields of Rat's Hippocampus. American Journal of Animal and Veterinary Sciences 2008;3:28-31.

45. Stehberg J, Moraga-Amaro R, Salazar C, Becerra A, Echeverría C, Orellana JA, et al. Release of gliotransmitters through astroglial connexin 43 hemichannels is necessary for fear memory consolidation in the basolateral amygdala. FASEB $\mathrm{J}$ 2012;26:3649-57.

46. Pinto-Duarte A, Roberts AJ, Ouyang K, Sejnowski TJ. Impairments in remote memory caused by the lack of Type 2 IP3 receptors. Glia 2019;67:1976-89. 
47. Holtzclaw LA, Pandhit S, Bare DJ, Mignery GA, Russell JT. Astrocytes in adult rat brain express type 2 inositol 1,4,5-trisphosphate receptors Glia 2002;39:69-84.
48. Sharp AH, Nucifora FC Jr, Blondel O, Sheppard CA, Zhang C, Snyder SH, et al. Differential cellular expression of isoforms of inositol 1,4,5-triphosphate receptors in neurons and glia in brain. J Comp Neurol 1999;406:207-20. 